\title{
Levels and distribution patterns of short chain chlorinated paraffins in sewage sludge of wastewater treatment plants in China
}

\author{
Lixi Zenga,b, Thanh Wang ${ }^{\mathrm{a}}$, Ting Ruan ${ }^{\mathrm{a}}$, Qian Liu ${ }^{\mathrm{a}}$, Yawei Wang ${ }^{\mathrm{a}, *}$, Guibin Jiang ${ }^{\mathrm{a}}$ \\ a State Key Laboratory of Environmental Chemistry and Ecotoxicology, Research Center for Eco-Environmental Sciences, Chinese Academy of Sciences, \\ P.O. Box 2871, Beijing 100085, China \\ ${ }^{\mathrm{b}}$ College of Chemistry and Chemical Engineering, Graduate University of Chinese Academy of Sciences, Beijing 100049, China
}

\section{A R T I C L E I N F O}

\section{Article history:}

Received 4 July 2011

Received in revised form

1 September 2011

Accepted 1 September 2011

\section{Keywords:}

Persistent organic pollutant

Short chain chlorinated paraffins

Wastewater treatment plants

Sewage sludge

\begin{abstract}
A B S T R A C T
Short chain chlorinated paraffins (SCCPs) are listed as persistent organic pollutant candidates in the Stockholm Convention and are receiving more and more attentions worldwide. In general, concentrations of contaminants in sewage sludge can give an important indication on their pollution levels at a local/regional basis. In this study, SCCPs were investigated in sewage sludge samples collected from 52 wastewater treatment plants in China. Concentrations of total SCCPs ( $\Sigma$ SCCPs) in sludge were in the range of $0.80-52.7 \mu \mathrm{g} / \mathrm{g}$ dry weight $(\mathrm{dw})$, with a mean value of $10.7 \mu \mathrm{g} / \mathrm{g} \mathrm{dw}$. Most of SCCPs in the sludge samples showed a similar congener distribution patterns, and $\mathrm{C}_{11}$ and $\mathrm{Cl}_{7,8}$ were identified as the dominant carbon and chlorine congener groups. Significant linear relationships were found among different SCCP congener groups $\left(r^{2} \geq 0.9\right)$. High concentrations of SCCPs in sewage sludge imply that SCCPs are widely present in China.
\end{abstract}

(c) 2011 Elsevier Ltd. All rights reserved.

\section{Introduction}

As a class of highly complex technical mixtures, chlorinated paraffins (CPs) contain thousands of isomers, diastereomers and enantiomers (Bayen et al., 2006; Pellizzato et al., 2007; Feo et al., 2009). The commercial mixtures of CPs are produced by chlorination of n-alkane feedstocks with carbon-chain lengths from 10 to 30 (Tomy et al., 1998). Up to now, more than two hundreds of commercial CP products have been used for different industrial applications, such as extreme pressure lubricant additive, plasticizers, flame retardants and paint additives, etc (Santos et al., 2006). In general, $\mathrm{CPs}$ are divided into short chain CPs ( $\mathrm{C}_{10-13}$, SCCPs), medium chain CPs ( $\mathrm{C}_{14-17}$, MCCPs) and long chain CPs ( $\mathrm{C}_{18-30}$, LCCPs) according to their carbon-chain lengths (Zencak and Oehme, 2006).

Due to widespread and unrestricted use in the past decades, CPs have been found widespread in the environment and have been detected in different environmental matrices, such as air (Peters et al., 2000; Barber et al., 2005), water (Coelhan, 2010), soil (Nicholls et al., 2001; Zeng et al., 2011a), sediments (Tomy et al., 1999; Marvin et al., 2003; Iozza et al., 2008), sludge (Stevens et al., 2003), biota (Tomy et al., 2000), terrestrial wildlife (Jansson et al., 1993) and human foods (Iino et al., 2005), and even in the

\footnotetext{
* Corresponding author.

E-mail address: ywwang@rcees.ac.cn (Y. Wang).
}

environment of remote areas (Tomy et al., 1999). Of all the CP mixtures, SCCPs tend to behave in a similar way to persistent organic pollutants (POPs), leading to some countries and organizations to impose regulation on the production and use of these compounds (Pellizzato et al., 2009). Because of their persistence (Iozza et al., 2008), toxicity (Cooley et al., 2001; Warnasuriya et al., 2010), bioaccumulation (Fisk et al., 1996; Houde et al., 2008; Zeng et al., 2011b) and potential for long-range transport abilities (Tomy et al., 1999), SCCPs have been listed as POP candidate by the Stockholm Convention. However, data on the distributions, environmental fate and toxicity of SCCPs are still scarce compared to other POPs, mainly due to the complexity of analytical methodologies (Eljarrat and Barcelo, 2006; Santos et al., 2006).

Release of SCCPs into the environment can occur during production, incorporation into polymers or products, and through usage and disposal or recycling of these products. The released SCCPs can finally enter the municipal wastewater network through atmospheric deposition or non-point source discharge, and accumulate in the wastewater treatment plants (WWTPs). Due to their high lipophilicity and environmental persistency, a large proportion of SCCPs tend to be preferentially partitioned or concentrated to high organic carbon-containing sewage sludge during wastewater treatment (Zeng et al., 2011b). Therefore, the concentrations of SCCPs in sewage sludge from WWTPs can give an important indication of the general exposure and usages of these contaminants and their pollution status in the region. However, up to now, 
levels and distribution of SCCPs in sewage sludge are only found in very limited works (Rieger and Ballschmiter, 1995; Nicholls et al., 2001; Stevens et al., 2003).

China is the largest producer of chlorinated paraffins in the world (De Boer et al., 2010), with most of the manufacturing plants located in the east of China. Since 1990, the annual production volumes of CPs are increasing rapidly (Zeng et al., 2011b). However, studies on SCCPs in the environment in China are still very limited. Only several studies on the distributions of SCCPs in e-waste dismantling areas, wastewater irrigated regions, and sediments have been reported recently (Yuan et al., 2010; Zeng et al., 2011a, 2011b).

The aim of this study is to assess the SCCPs load in sewage sludge of WWTPs collected from different cities in China. Congener group patterns were also studied to investigate potential geographic distributions. It is hoped that the results in this study can provide valuable information to indicate the pollution levels and distribution patterns of SCCPs in the human living environment in China.

\section{Materials and methods}

\subsection{Materials, standards and reagents}

All reagents (cyclohexane, dichloromethane, $n$-hexane) were pesticide residue grade and purchased from Fisher Scientific (Hampton, NH). Silica gel and Florisil (60-100 mesh) were obtained from Merck (Whitehouse Station, NJ). Commercial standards of SCCPs $\left(\mathrm{C}_{10-13}, 51.5 \%, 55.5 \%\right.$ and $63.0 \%$ chlorine content, $100 \mathrm{ng} / \mu \mathrm{L} ; \mathrm{C}_{10}$, $50.2 \%, 55.0 \%, 60.1 \%$ and $65.0 \%$ chlorine content, $10 \mathrm{ng} / \mu \mathrm{L} ; \mathrm{C}_{11}, 50.2 \%, 55.2 \%, 60.5 \%$ and $65.3 \%$ chlorine content, $10 \mathrm{ng} / \mu \mathrm{L} ; \mathrm{C}_{12}, 50.2 \%, 55.0 \%, 65.1 \%$ and $70.0 \%$ chlorine content, $10 \mathrm{ng} / \mu \mathrm{L} ; \mathrm{C}_{13}, 50.2 \%, 55.0 \%, 60.0 \%$ and $65.2 \%$ chlorine content, $10 \mathrm{ng} / \mu \mathrm{L}$ ) and MCCPs mixtures $\left(\mathrm{C}_{14-17}, 42.0 \%, 52.0 \%\right.$ and $57.0 \%$ chlorine content, $\left.100 \mathrm{ng} / \mu \mathrm{L}\right)$ in cyclohexane as well as $\varepsilon$-hexachlorocyclohexane $(\varepsilon-\mathrm{HCH}$, solution in cyclohexane, $10 \mathrm{ng} / \mu \mathrm{L})$ were purchased from Ehrenstorfer GmbH (Augsburg, Germany). ${ }^{13} \mathrm{C}_{10}$-trans-chlordane (99\%) in $n$-nonane was supplied by Cambridge Isotope Laboratories (Andover, USA).

\subsection{Sampling site and sample collection}

A total of 52 WWTPs were selected for collection of sewage sludge samples from 25 cities in China during the period of August 2010 to March 2011. The sampling sites cover 13 Chinese provinces and most of them are located in eastern China. Fig. 1 shows the detailed distribution of the Chinese manufacturing plants of CPs and the sampling locations from different provinces in this study. All sludge samples were freeze-dried and homogenized, then stored in a freezer at $-20{ }^{\circ} \mathrm{C}$ until analysis. A survey form was also associated with each sample. Details of each WWTPs in regards to treatment capacity, serving population, sewage sources (domestic industrial, or combined), and type of sludge treatment are supplied in Table SI-1 in Supplementary material.

\subsection{Sample pretreatment}

Sample pretreatment for SCCP analysis were based on the procedure described previously with some modifications (Zeng et al., 2011a). Prior to extraction, $0.2 \mathrm{~g}$ of sludge sample was mixed with $10 \mathrm{~g}$ anhydrous sodium sulfate, spiked with $10 \mathrm{ng}$ ${ }^{13} \mathrm{C}_{10}$-trans-chlordane surrogate standard and extracted by accelerated solvent extractor (ASE, Dionex ASE 350, Canada) with mixture solvent of dichloromethane/ hexane $(1: 1, v / v)$. After the extraction, the extract was rotary-evaporated to about $2 \mathrm{~mL}$ and then subjected to clean-up using a multilayer silica-Florisil composite column, which was filled with $3 \mathrm{~g}$ Florisil, $2 \mathrm{~g}$ activated silica gel, $5 \mathrm{~g}$ acid silica gel $(30 \%, \mathrm{w} / \mathrm{w})$ and $4 \mathrm{~g}$ anhydrous sodium sulfate from bottom to top. The column was pre-cleaned with $50 \mathrm{~mL}$ hexane, and then eluted in sequence with $40 \mathrm{~mL}$ of hexane (F1) and $100 \mathrm{~mL}$ of dichloromethane/hexane (1:1, v/v) (F2). CPs eluted in the second fraction F2 and the solvent was exchanged to cyclohexane and concentrated to a final volume $200 \mu \mathrm{L}$. Finally, $10 \mathrm{ng} \varepsilon-\mathrm{HCH}$ was added as an internal standard to determine the recoveries before instrument analysis.

\subsection{Identification and quantification}

All analyses were performed on high-resolution gas chromatography/electron capture negative ion low-resolution mass spectrometry (HRGC/ECNI-LRMS, Agilent, USA) using selected ion monitoring (SIM) mode. Under ECNI conditions, the most and second most abundant isotope ions of $[\mathrm{M}-\mathrm{Cl}]^{-}$for each congener group were selected for quantification and confirmation, respectively. SCCP and MCCP congeners with 5-10 chlorine atoms were analyzed for all sludge samples. In order to ensure the instrument sensitivity, SCCP and MCCP congeners were divided into four
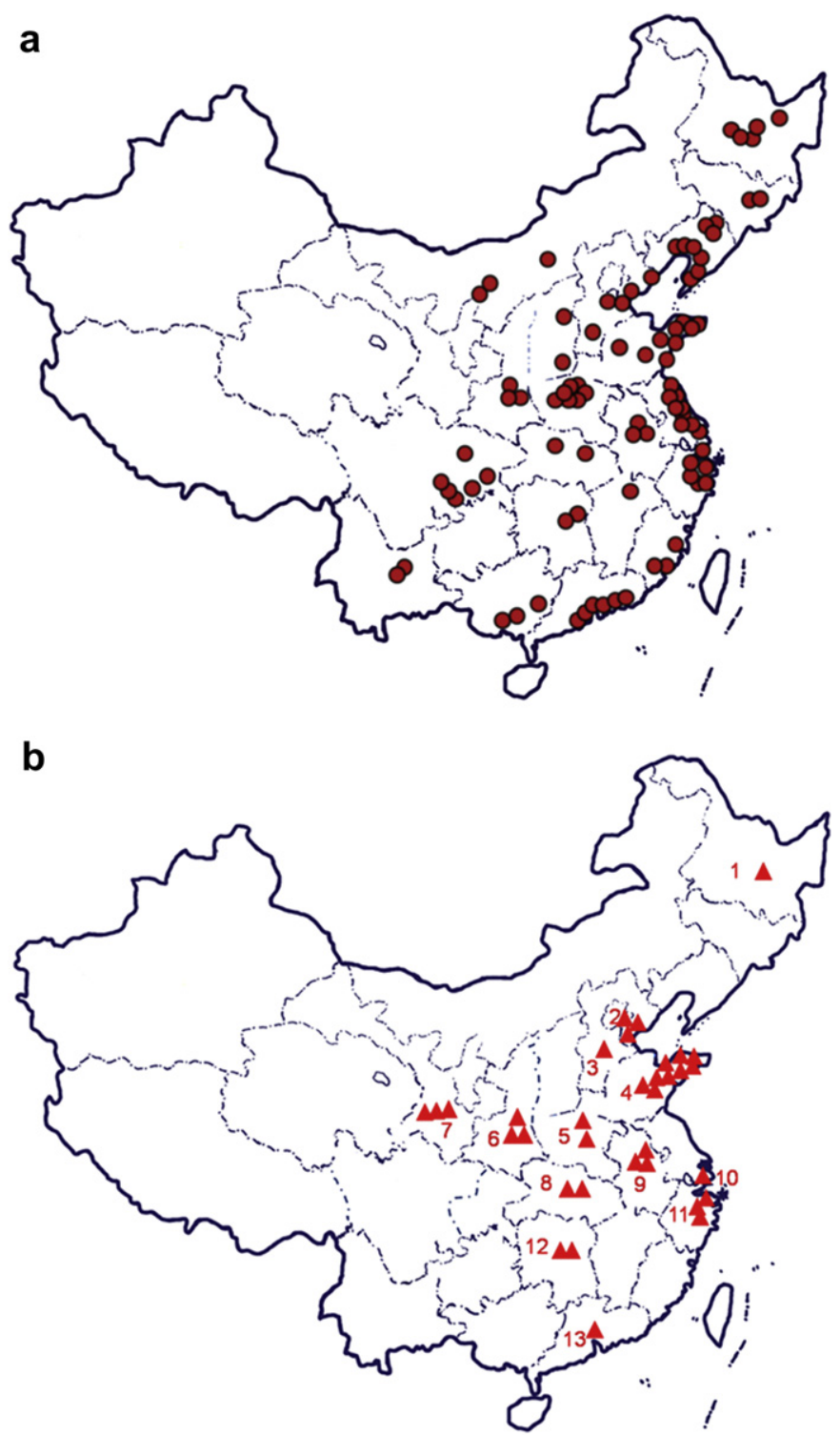

Fig. 1. (a) Distribution of manufacturing plants of CPs in China; (b) Sample sites of WWTPs in different provinces in China: 1 Helongjiang; 2 Beijing; 3 Hebei; 4 Shandong; 5 Henan; 6 Shanxi; 7 Gansu; 8 Hubei; 9 Anhui; 10 Shanghai; 11 Zhejiang; 12 Hunan; 13 Guangdong.

groups by the optimized combinations $\left(C_{10}\right.$ and $C_{15} ; C_{11}$ and $C_{16} ; C_{12}$ and $C_{17} ; C_{13}$ and $\mathrm{C}_{14}$ ) and subjected to analysis by four individual injections. Detailed information on instrument analysis is available in our previous work (Zeng et al., 2011a).

SCCP/MCCP congener groups in the sludge samples were identified by comparing the extracted ion chromatogram with those of standard CPs (Reth and Oehme, 2004). The actual integrated signals for each CP congener were obtained by correcting the peak areas of $[\mathrm{M}-\mathrm{Cl}]^{-}$ions from isotopic abundance and response factors. The sum of SCCP concentration ( $\mathrm{SCCPP}$ ) were calculated based on the quantification procedure described by Reth and Oehme (Reth et al., 2005).

\subsection{Quality assurance and quality control (QA/QC)}

Strict quality assurance and control measures were implemented to ensure the identification and accurate quantification of the analysis. All glassware and sodium sulfate were solvent rinsed and heated overnight at $450{ }^{\circ} \mathrm{C}$ before usage. Each batch of 10 samples included one procedural blank to check potential contamination. Method blanks were near or below the limit of detection (LOD), which was estimated at $100 \mathrm{ng} / \mathrm{g}$ for total SCCPs. The quantitative results were not blank corrected in this study. The recoveries of standards in spiked samples were within $80-105 \%$. Repeatability of the GC-MS measurement was tested and relative standard deviation was in the range of $5-10 \%(n=8)$. 


\section{Results and discussion}

All concentrations were reported on a dry weight (dw) basis. The results indicated that the $\mathrm{CP}$ mixtures in sewage sludge were mainly composed by SCCPs. MCCPs could be detected in only some samples at low levels. Therefore in this work, only the concentrations of SCCPs in sewage sludge were presented and discussed.

\subsection{SCCPs levels in sewage sludge}

The results showed that SCCPs could be detected in all sludge samples. The concentrations for the different carbon chain homologues $\left(\mathrm{C}_{10-13}\right)$ and total SCCPs ( $\sum \mathrm{SCCPs}$ ) are summarized in Table SI- 2 . The levels of $\sum$ SCCPs in sewage sludge ranged from 0.80 to $52.7 \mu \mathrm{g} / \mathrm{g}$, with the average concentration at $10.7 \mu \mathrm{g} / \mathrm{g}$, which are much higher than other contaminants such as polychlorinated biphenyls (PCBs) and organochlorine pesticides (OCPs) in our previous studies (Wang et al., 2007). The highest concentrations of $\sum$ SCCPs were found in two municipal WWTPs located at Xi'an national high-tech development zone in Shanxi Province, which were up to 52.7 and $42.8 \mu \mathrm{g} / \mathrm{g}$, respectively. High levels of SCCPs found in this district might originate from several sources. Based on the background information of the two WWTPs (Table SI-2), we found that about half of the influents came from industrial effluents. Several CP manufacturing plants were located in the industrial zone of this city. Other potential sources could be from the large number of high-tech enterprises associated with CPs in this area.

Among all the sampling sites, Shandong province should be paid more attention, since it represents one of the major production bases of CPs (Tang and Yao, 2005). In this study, 21 sewage sludge samples of WWTPs were collected from 10 different cities in Shandong (Table SI-1). There was a slight variation of SCCP concentrations among the 21 sewage sludge except two samples with high levels of SCCPs (WWTP. No 21 and 26). The maximum concentration of SCCPs in the sludge from this province was $14.1 \mu \mathrm{g} / \mathrm{g}$ in Jining City and the minimum was $0.8 \mu \mathrm{g} / \mathrm{g}$ in Dezhou
City (Table SI-2). Generally, no significant differences of SCCP levels can be found in sludge collected from different WWTPs in the same city. Comparing to other provinces, the samples from Shandong Province did not show high levels of SCCPs although it is the main manufacturing base of CPs in China. On the contrary, it is noticeable that, the sludge samples in other districts, such as Beijing, where almost no CP manufacturing plants exist, contained relatively higher concentrations of SCCPS. This phenomenon suggests that release of $\mathrm{CPs}$ into the environment during $\mathrm{CP}$ production might not be a main source for SCCPs in sewage sludge of WWTPs. No clear-cut geographic distribution characteristics were observed among the sampling sites, but samples from densely populated area or/and high-tech industrial zone generally exhibited relatively higher SCCP levels.

Fig. 2 illustrates the frequency distributions of concentrations for five dominating homologues $\left(\mathrm{C}_{10}, \mathrm{C}_{11}, \mathrm{C}_{12}, \mathrm{Cl}_{7}\right.$, and $\left.\mathrm{Cl}_{8}\right)$ and $\sum$ SCCPs in sewage sludge. The concentrations of $\mathrm{C}_{10}$ ranged from 0.20 to $13.9 \mu \mathrm{g} / \mathrm{g}$ (mean $2.80 \mu \mathrm{g} / \mathrm{g}$ ). $96 \%$ of $\mathrm{C}_{10}$ concentrations were in the range of $0.20-6.00 \mu \mathrm{g} / \mathrm{g}$. The $C_{11}$ homologue was found to be the most abundant carbon homologue in sludge samples. The concentrations of $C_{11}$ ranged from 0.30 to $15.8 \mu \mathrm{g} / \mathrm{g}$ (mean $3.60 \mu \mathrm{g} /$ g). $94 \%$ of $C_{11}$ concentrations were in the range of $0.30-8.00 \mu \mathrm{g} / \mathrm{g}$, and $6 \%$ of them were higher than $10.0 \mu \mathrm{g} / \mathrm{g}$. The concentrations of $C_{12}$ ranged from 0.20 to $12.8 \mu \mathrm{g} / \mathrm{g}$ (mean $2.40 \mu \mathrm{g} / \mathrm{g}$ ), while $90 \%$ of $C_{12}$ concentrations were centered in the range of $0.20-4.00 \mu \mathrm{g} / \mathrm{g}$. Moreover, $\mathrm{Cl}_{7}$ and $\mathrm{Cl}_{8}$ were the predominant chlorine homologues, which were in the concentration range of $0.30-17.3 \mu \mathrm{g} / \mathrm{g}$ and $0.20-18.1 \mu \mathrm{g} / \mathrm{g}$, respectively. $92 \%$ of $\mathrm{Cl}_{7}$ concentrations were in the range of $0.30-8.00 \mu \mathrm{g} / \mathrm{g}$, with $40 \%$ of them higher than $4.00 \mu \mathrm{g} / \mathrm{g}$. Similarly, $96 \%$ of $\mathrm{Cl}_{8}$ concentrations were in the range of $0.20-8.00 \mu \mathrm{g} / \mathrm{g}$, but only $27 \%$ of them were higher than $4.00 \mu \mathrm{g} / \mathrm{g}$.

As shown in Fig. 2, more than $90 \%$ of $\sum$ SCCPs were in the range of $0.80-20.0 \mu \mathrm{g} / \mathrm{g}$. The distribution of concentrations for $\sum$ SCCPs in sludge samples were also summarized as medians, quartiles and ranges with box-whisker plots (Fig. SI-1). The statistical results clearly indicated the concentrations of $\sum$ SCCPs in $75 \%$ samples
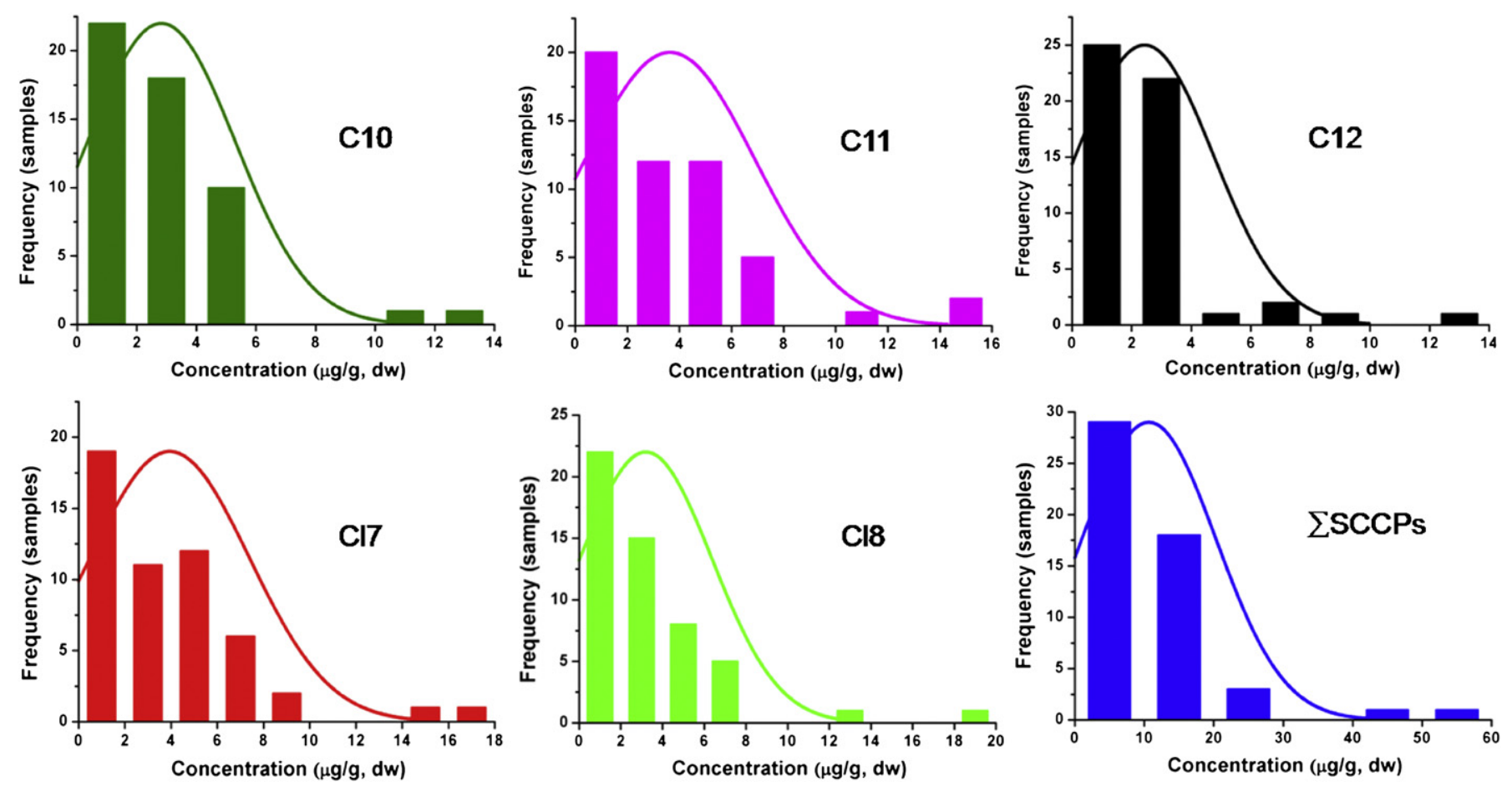

Fig. 2. Frequency distributions of concentrations for five dominating homologues $\left(C_{10}, C_{11}, C_{12}, C_{17}\right.$, and $\left.C_{18}\right)$ and $\sum S C C P s$ in sewage sludge in China. 
were lower than $12.5 \mu \mathrm{g} / \mathrm{g}$, and about $20 \%$ of the samples were in the range of $12.5-22.5 \mu \mathrm{g} / \mathrm{g}$. Only $5 \%$ of samples showed SCCP concentrations higher than $22.5 \mu \mathrm{g} / \mathrm{g}$. These results implied that concentrations lower than $20.0 \mu \mathrm{g} / \mathrm{g}$ could be representative of the typical SCCP levels in most sewage sludge from WWTPs in China.

Compared to other POPs, such as polybrominated diphenyl ethers (PBDEs) and PCBs (Clarke et al., 2008; Kupper et al., 2008; Diaz-Cruz et al., 2009; Guo et al., 2009), information on SCCP concentrations in sewage sludge are very scarce. In U.K., a survey of the digested sludge from 14 WWTPs revealed that SCCP concentrations ranged from 7 to $200 \mu \mathrm{g} / \mathrm{g} \mathrm{dw}$ (Stevens et al., 2003), and the range of concentrations is consistent with those previous measured in sewage sludge $(1.8-93 \mu \mathrm{g} / \mathrm{g} \mathrm{dw})$ from England and Wales (Nicholls et al., 2001). Our work indicated that SCCP concentrations in sewage sludge in China were comparable to the reported data, but the average levels were lower than those measured in the U.K.

\subsection{Congener distribution patterns in sewage sludge}

The SCCP congener distribution patterns of sewage sludge samples from 52 WWTPs in different cities were also analyzed. Fig. 3 shows both the carbon homologue composition and chlorine homologue composition profiles. In general, the congener compositions in all sewage sludge were similar among different WWTPs, although some of them are located in different districts and receive different types of sewage sources (domestic, industrial, or combined) (Table SI-1). Composition analysis indicated that the most abundant group of SCCPs in sludge samples was $C_{11}$, which accounted in average for $34 \%$ of $\Sigma$ SCCPs. Other abundant carbon homologues were $\mathrm{C}_{10}$ and $\mathrm{C}_{12}$, which accounted for $27 \%$ and $23 \%$ of total SCCPs, respectively. The concentration distributions for four carbon chain homologues by box-whisker plots (Fig. SI-1a) also indicated that their median concentrations were in the following order: $\mathrm{C}_{11}>\mathrm{C}_{10} \approx \mathrm{C}_{12}>\mathrm{C}_{13}$.

The chlorine homologue composition profiles in most of sludge samples also showed similar distribution pattern (Fig. 3). The $\mathrm{Cl}_{7}$ (mean contribution of $37 \%$ ) and $\mathrm{Cl}_{8}(29 \%)$ were the most dominant congener groups in all samples except one sample from Ningbo city (No 32), which mainly receives dyeing wastewater discharged from textile industry. Other abundant chlorine homologues were $\mathrm{Cl}_{6}$ and $\mathrm{Cl}_{9}$, which accounted for $16 \%$ and $10 \%$ of $\Sigma$ SCCPs, respectively. Both the low chlorinated congener $\mathrm{Cl}_{5}$ and the high chlorinated congeners $\mathrm{Cl}_{10}$ accounted for less than $10 \%$ of total SCCPs. The homologue distribution pattern in sewage sludge were consistent with the composition of commercial standards and technical SCCP mixtures (Reth and Oehme, 2004). The concentration distributions for six chlorine atom homologues in Fig. SI-1b indicated that their median concentrations were in the order of $\mathrm{Cl}_{7}>\mathrm{Cl}_{8}>\mathrm{Cl}_{6}>\mathrm{Cl}_{9}>$ $\mathrm{Cl}_{5}>\mathrm{Cl}_{10}$. The main congeners $\mathrm{Cl}_{7}$ and $\mathrm{Cl}_{8}$ showed obviously higher mean concentrations than other chlorine atom homologues. To our knowledge, this is also the first study on the distributions of different homologues in sewage sludge.

Figs. 4 and 5 shows the representative congener group abundance profiles categorized by carbon and chlorine atom numbers in four sludge samples, which were collected from Beijing (No. 3), Shandong (No. 17), Guangdong (No. 45) and Shanxi Province (No. 46). These four sampling sites respectively represent locations from the northern, eastern, southern and eastern parts of China. Among the four provinces, Beijing and Guangdong are characterized by densely population and high industrialization, while Shandong is a major production base of CPs in China. As shown in the carbon congener group abundance profiles (Fig. 4), the composition distributions of congeners were obviously predominated by
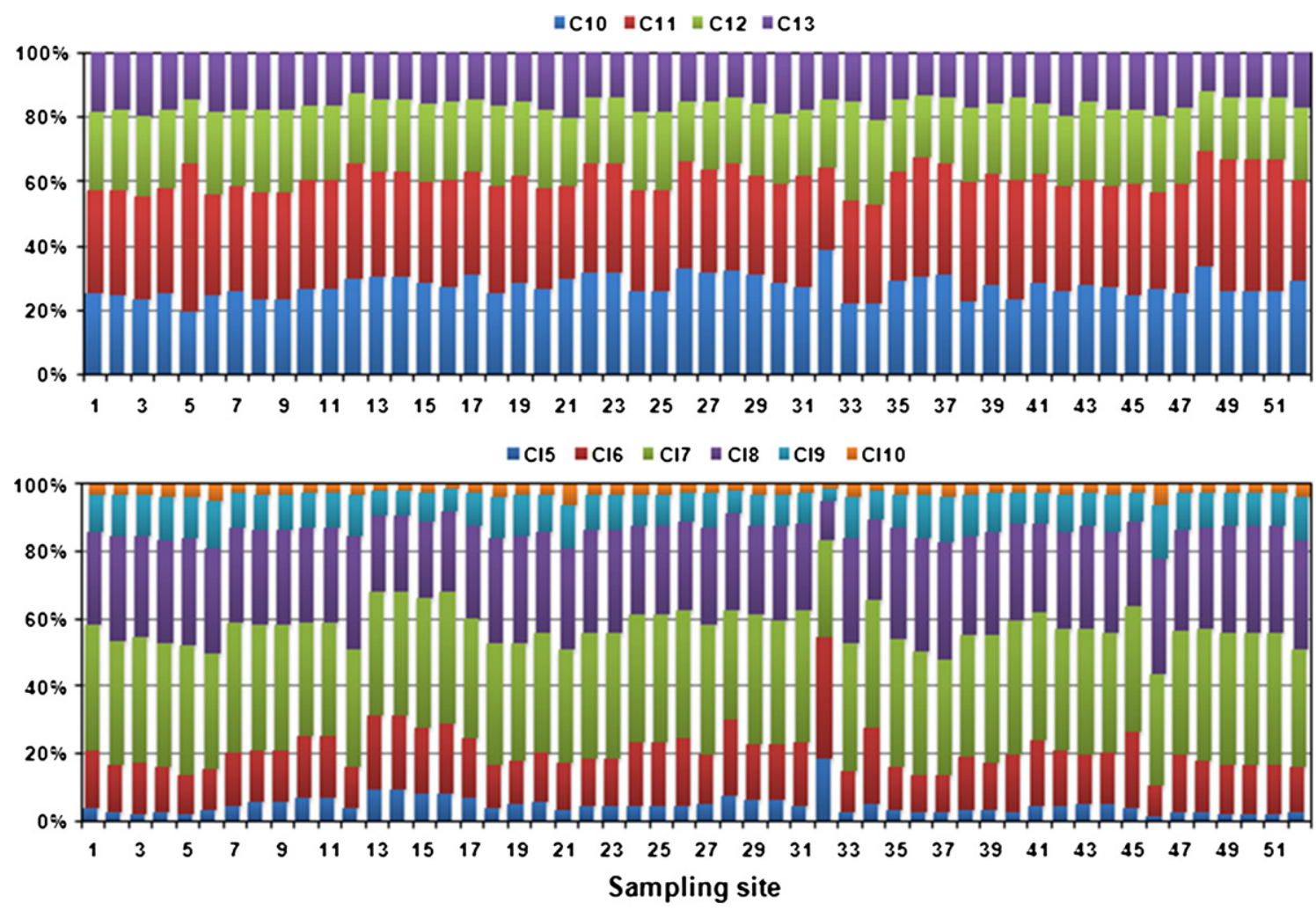

Fig. 3. Composition profiles of carbon homologues $\left(C_{10}-C_{13}\right)$ and chlorine homologue $\left(C_{15}-C_{10}\right)$ for total 52 sewage sludge samples in China. 

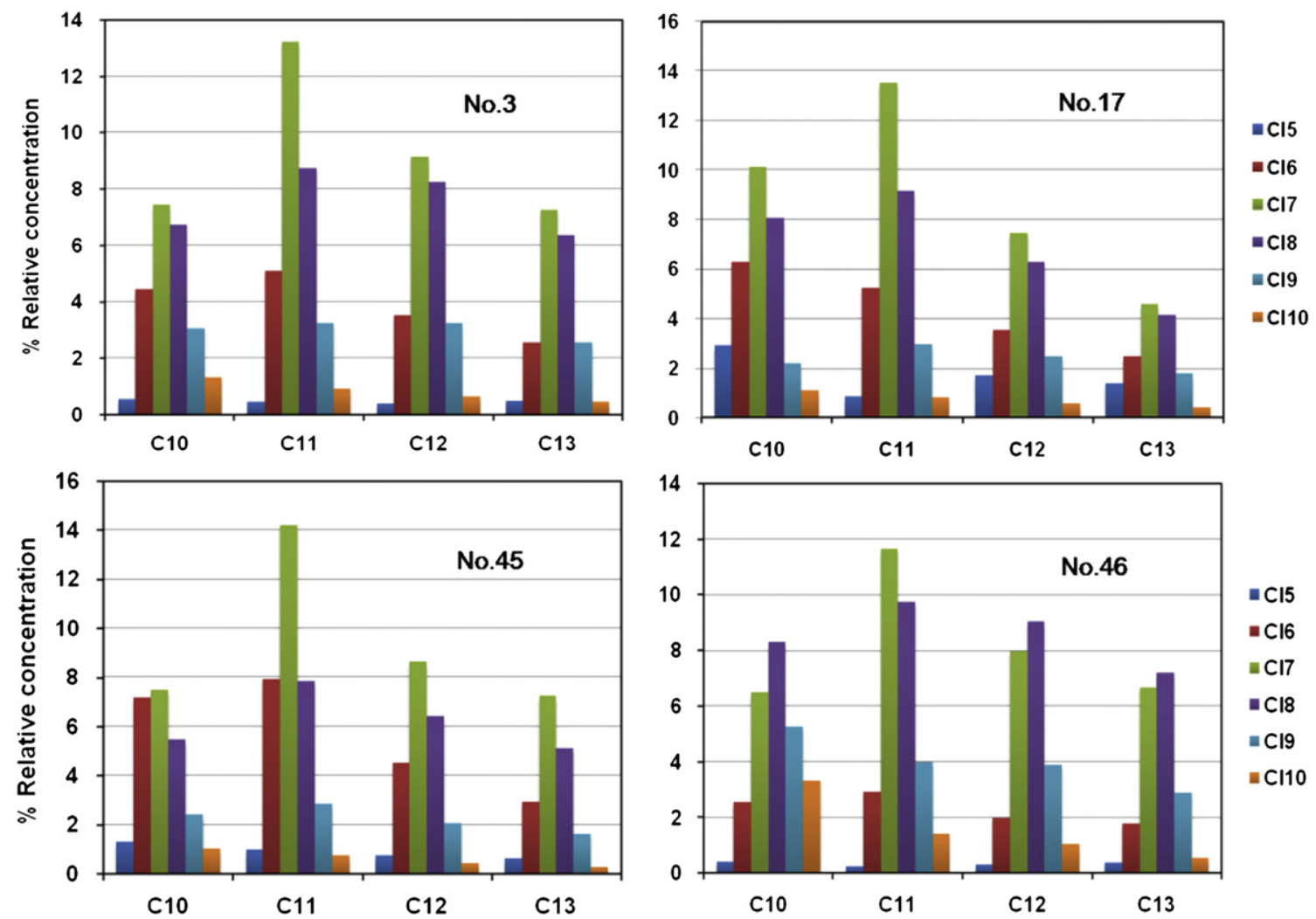

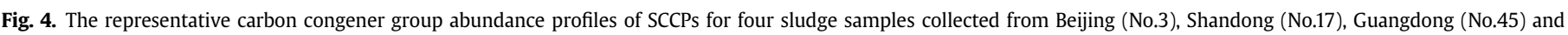
Shanxi Province (No.46), respectively.
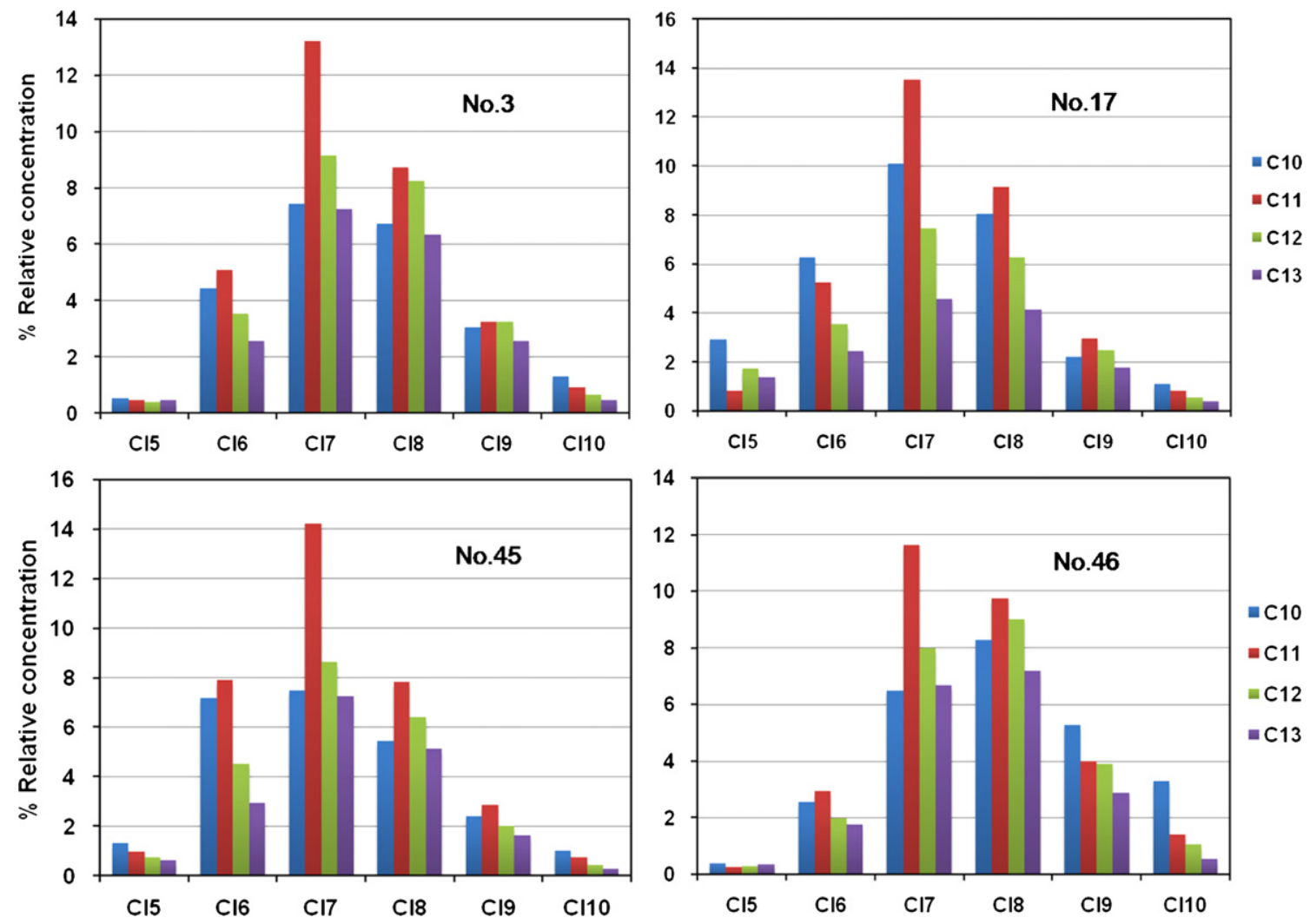

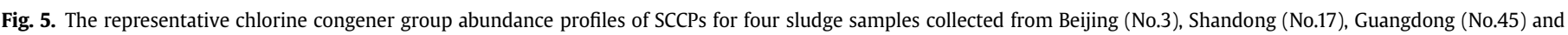
Shanxi Province (No.46), respectively. 
medium chlorinated congeners $\left(\mathrm{Cl}_{7-8}\right)$ within the individual carbon chain groups $\left(C_{10}, C_{11}, C_{12}\right.$, and $\left.C_{13}\right)$. Furthermore, this congener distribution pattern was more clearly reflected in the chlorine congener group abundance profiles (Fig. 5). These specific congener distributions of $\sum$ SCCPs in sewage sludge may be influenced by the difference in composition of technical CP mixtures produced and used in China.

\subsection{Correlation analysis}

The relationships among different SCCP congener groups were evaluated using linear regression analysis. Significant linear relationships were found among different carbon chain groups $\left(C_{10}, C_{11}\right.$, $\mathrm{C}_{12}$, and $\mathrm{C}_{13}$ ). Besides, significant linear relationships were also found among different chlorine congener groups. The correlation coefficient $\left(R^{2}\right)$ among these homologues varied from 0.90 to 0.97 $(p<0.05)$. Furthermore, in order to examine the potential factors that affect the SCCP levels in sewage sludge, principal component analysis (PCA) was executed using SPSS 16.0. The results indicated concentrations of different SCCP homologues in sludge have no significant relationships with the WWTP location, treatment capacity and serving population $(p>0.05)$. This is consistent with the results of a survey of digested sludge from 14 WWTPs in U.K (Stevens et al., 2003).

\section{Conclusions}

SCCPs could be detected in all sewage sludge samples collected from 52 WWTPs in 25 cities in China. The levels were comparable to those found previously in U.K., although China is the largest production country of CPs in the world. The sludge samples from different regions showed very similar homologue profiles of SCCPs, with $\mathrm{C}_{11}$ and $\mathrm{Cl}_{7,8}$ as the dominant congeners. Significant linear correlations among different congener groups were observed. The range of SCCPs in sewage sludge implied that they are widespread in our human society. More attention should be paid to assess the risk of SCCPs in sludge, with the aim of reducing the potential environmental and health effects when these compounds re-enter the ambient environment through sludge treatment.

\section{Acknowledgments}

This work was jointly supported by the National Natural Science Foundation $(21007078,21007085,21077114$, and 20890111), the National Basic Research Program of China (2009CB421605), Chinese Academy of Sciences (KZCX2-YW-QN409), and the China Postdoctoral Science Foundation (20090460544, 201003166).

\section{Appendix. Supplementary material}

Supplementary material associated with this article can be found.in doi:10.1016/j.envpol.2011.09.004.

\section{References}

Barber, J.L., Sweetman, A.J., Thomas, G.O., Braekevelt, E., Stern, G.A., Jones, K.C. 2005. Spatial and temporal variability in air concentrations of short-chain $\left(\mathrm{C}_{10}-\mathrm{C}_{13}\right)$ and medium-chain $\left(\mathrm{C}_{14}-\mathrm{C}_{17}\right)$ chlorinated n-alkanes measured in the UK atmosphere. Environ. Sci. Technol. 39, 4407-4415.

Bayen, S., Obbard, J.P., Thomas, G.O., 2006. Chlorinated paraffins: a review of analysis and environmental occurrence. Environ. Int. 32, 915-929.

Clarke, B., Porter, N., Symons, R., Marriott, P., Ades, P., Stevenson, G., Blackbeard, J., 2008. Polybrominated diphenyl ethers and polybrominated biphenyls in Australian sewage sludge. Chemosphere 73, 980-989.

Coelhan, M., 2010. Levels of chlorinated paraffins in water. Clean-Soil Air Water 38, $452-456$.
Cooley, H.M., Fisk, A.T., Wiens, S.C., Tomy, G.T., Evans, R.E., Muir, D.C.G., 2001. Examination of the behavior and liver and thyroid histology of juvenile rainbow trout (Oncorhynchus mykiss) exposed to high dietary concentrations of $\mathrm{C}_{10^{-}}, \mathrm{C}_{11^{-}}, \mathrm{C}_{12^{-}}$and $\mathrm{C}_{14}$-polychlorinated $\mathrm{n}$-alkanes. Aquat. Toxicol. 54, 81-99.

De Boer, J., El-Sayed Ali, T., Fiedler, H., Legler, J., Muir, D.C., Nikiforov, V.A., Tomy, G.T., Tsunemi, K., 2010. Chlorinated paraffins. In: De Boer, J. (Ed.), The Handbook of Environmental Chemistry. Chlorinated Paraffins, vol. 10. Springer-Verlag, Berlin: Berlin/Heidelberg.

Diaz-Cruz, M.S., Garcia-Galan, M.J., Guerra, P., Jelic, A., Postigo, C., Eljarrat, E., Farre, M., de Alda, M.J.L., Petrovic, M., Barcelo, D., 2009. Analysis of selected emerging contaminants in sewage sludge. Trac-Trends Anal. Chem. 28, 1263-1275.

Eljarrat, E., Barcelo, D., 2006. Quantitative analysis of polychlorinated n-alkanes in environmental samples. Trac-Trends Anal. Chem. 25, 421-434.

Feo, M.L., Eljarrat, E., Barcelo, D., 2009. Occurrence, fate and analysis of polychlorinated n-alkanes in the environment. Trac-Trends Anal. Chem. 28, 778-791.

Fisk, A.T., Cymbalisty, C.D., Bergman, A., Muir, D.C.G., 1996. Dietary accumulation of C-12- and C-16-chlorinated alkanes by juvenile rainbow trout (Oncorhynchus mykiss). Environ. Toxicol. Chem. 15, 1775-1782.

Guo, L., Zhang, B., Xiao, K., Zhang, Q.H., Zheng, M.H., 2009. Levels and distributions of polychlorinated biphenyls in sewage sludge of urban wastewater treatment plants. J. Environ. Sciences-China 21, 468-473.

Houde, M., Muir, D.C.G., Tomy, G.T., Whittle, D.M., Teixeira, C., Moore, S., 2008. Bioaccumulation and trophic magnification of short- and medium-chain chlorinated paraffins in food webs from Lake Ontario and Lake Michigan. Environ. Sci. Technol. 42, 3893-3899.

Iino, F., Takasuga, T., Senthilkumar, K., Nakamura, N., Nakanishi, J., 2005. Risk assessment of short-chain chlorinated paraffins in Japan based on the first market basket study and species sensitivity distributions. Environ. Sci. Technol. 39, 859-866.

Iozza, S., Muller, C.E., Schmid, P., Bogdal, C., Oehme, M., 2008. Historical profiles of chlorinated paraffins and polychlorinated biphenyls in a dated sediment core from Lake Thun (Switzerland). Environ. Sci. Technol. 42, 1045-1050.

Jansson, B., Andersson, R., Asplund, L., Litzen, K., Nylund, K., Sellstrom, U., Uvemo, U.B., Wahlberg, C., Wideqvist, U., Odsjo, T., Olsson, M., 1993. Chlorinated and brominated persistent organic compounds in biological samples from the environment. Environ. Toxicol. Chem. 12, 1163-1174.

Kupper, T., de Alencastro, L.F., Gatsigazi, R., Furrer, R., Grandjean, D., Tarradellas, J., 2008. Concentrations and specific loads of brominated flame retardants in sewage sludge. Chemosphere 71, 1173-1180.

Marvin, C.H., Painter, S., Tomy, G.T., Stern, G.A., Braekevelt, E., Muir, D.C.G., 2003. Spatial and temporal trends in short-chain chlorinated paraffins in Lake Ontario sediments. Environ. Sci. Technol. 37, 4561-4568.

Nicholls, C.R., Allchin, C.R., Law, R.J., 2001. Levels of short and medium chain length polychlorinated n-alkanes in environmental samples from selected industrial areas in England and Wales. Environ. Pollut. 114, 415-430.

Pellizzato, F., Ricci, M., Held, A., Emons, H., 2007. Analysis of short-chain chlorinated paraffins: a discussion paper. J. Environ. Monit. 9, 924-930.

Pellizzato, F., Ricci, M., Held, A., Emons, H., Bohmer, W., Geiss, S., Iozza, S., Mais, S., Petersen, M., Lepom, P., 2009. Laboratory intercomparison study on the analysis of short-chain chlorinated paraffins in an extract of industrial soil. Trac-Trends Anal. Chem. 28, 1029-1035.

Peters, A.J., Tomy, G.T., Jones, K.C., Coleman, P., Stern, G.A., 2000. Occurrence of C$10-\mathrm{C}-13$ polychlorinated n-alkanes in the atmosphere of the United Kingdom. Atmos. Environ. 34, 3085-3090.

Reth, M., Oehme, M., 2004. Limitations of low resolution mass spectrometry in the electron capture negative ionization mode for the analysis of shortand medium-chain chlorinated paraffins. Anal. Bioanal. Chem. 378, 1741-1747.

Reth, M., Zencak, Z., Oehme, M., 2005. New quantification procedure for the analysis of chlorinated paraffins using electron capture negative ionization mass spectrometry. J. Chromatogr. A 1081, 225-231.

Rieger, R., Ballschmiter, K., 1995. Semivolatile organic compounds - polychlorinated dibenzo-p-dioxins. (PCDD), dibenzofurans (PCDF), biphenyls (PCB), hexachlorobenzene (HCB), 4,4'-DDE and chlorinated paraffins (CP) - as markers in sewer films. Fresenius J. Anal. Chem. 352, 715-724.

Santos, F.J., Parera, J., Galceran, M.T., 2006. Analysis of polychlorinated n-alkanes in environmental samples. Anal. Bioanal. Chem. 386, 837-857.

Stevens, J.L., Northcott, G.L., Stern, G.A., Tomy, G.T., Jones, K.C., 2003. PAHs, PCBs, PCNs, organochlorine pesticides, synthetic musks, and polychlorinated n-alkanes in UK sewage sludge: survey results and implications. Environ. Sci. Technol. 37, 462-467.

Tang, E.T., Yao, L.Q., 2005. Industry status of chlorinated paraffin and its development trends. China Chlor - Alkali 2,1-3. in Chinese.

Tomy, G.T., Fisk, A.T., Westmore, J.B., Muir, D.C., 1998. Environmental chemistry and toxicology of polychlorinated n-alkanes. Rev. Environ. Contam. Toxicol. 158, $53-128$

Tomy, G.T., Muir, D.C.G., Stern, G.A., Westmore, J.B., 2000. Levels of $C_{10}-C_{13}$ polychloro-n-alkanes in marine mammals from the Arctic and the St. Lawrence River estuary. Environ. Sci. Technol. 34, 1615-1619.

Tomy, G.T., Stern, G.A., Lockhart, W.L., Muir, D.C.G., 1999. Occurrence of $C_{10}-C_{13}$ polychlorinated n-alkanes in Canadian midlatitude and arctic lake sediments. Environ. Sci. Technol. 33, 2858-2863. 
Wang, Y.W., Zhang, Q.H., Lv, J.X., Li, A., Liu, H.X., Li, G.G., Jiang, G.B., 2007. Polybrominated diphenyl ethers and organochlorine pesticides in sewage sludge of wastewater treatment plants in China. Chemosphere 68, 1683-1691.

Warnasuriya, G.D., Elcombe, B.M., Foster, J.R., Elcombe, C.R., 2010. A Mechanism for the induction of renal tumours in male Fischer 344 rats by short-chain chlorinated paraffins. Arch. Toxicol. 84, 233-243.

Yuan, B., Wang, Y.W., Fu, J.J., Zhang, Q.H., Jiang, G.B., 2010. An analytical method for chlorinated paraffins and their determination in soil samples. Chin. Sci. Bull. 55 , 2396-2402.
Zencak, Z., Oehme, M., 2006. Recent developments in the analysis of chlorinated paraffins. Trac-Trends Anal. Chem. 25, 310-317.

Zeng, L.X., Wang, T., Han, W.Y., Yuan, B., Liu, Q., Wang, Y.W., Jiang, G.B., 2011a. Spatial and vertical distribution of short chain chlorinated paraffins in soils from wastewater irrigated farmlands. Environ. Sci. Technol. 45, 2100-2106.

Zeng, L.X., Wang, T., Wang, P., Liu, Q., Han, S.L., Yuan, B., Zhu, N.l., Wang, Y.W. Jiang, G., 2011b. Distribution and trophic transfer of short-chain chlorinated paraffins in an aquatic ecosystem receiving effluents from a sewage treatment plant. Envion. Sci. Technol. 45, 5529-5535. 